\title{
PIGMENTONTWIKKELING EN HUIDGROEI BIJ CHIROPTEREN
}

DOOR

\author{
J. B O E KE \\ UTRECHT
}

(Mế 4 tekstfiguren.) $•$

Hoezeer ook dikwijls de huidpigmentatie aan de beharing is gebonden, de verdeeling en rangschikking van het huidpigment door den haargroei wordt bepaald, wijken toch de phylogenetische beteekenis en de waarde van beide verschijnselen ver uiteen. Hier ter plaatse op de algemeen phylogenetische beteekenis van de beharing der zoogdieren te wijzen, zou overbodig zijn. Want wij denken onmiddellijk aan het onderzoek van DE MEIJERE, over de rangschikking van de haren der zoogdieren, nu reeds zoovele jaren geleden uit het laboratorium van Prof. WEBER voortgekomen. En trouwens, men behoeft slechts eens bij een menschelijk foetus van bijv. 3 maanden met een sterke loupe de rangschikking van de haren in aanleg te hebben bezien, en waar te nemen die bijna wiskundig zuivere rangschikking van den haaraanleg in regelmatig afwisselende rijen van groepjes van 5 en 3 haren, om weer onder den indruk te geraken van dien verwonderlijken regelmaat en van het merkwaardig conservatieve karakter, dat de huidbeharing zelfs bij de hoogst ontwikkelde zoogdieren vertoont.

De beteekenis van de pigmentatie, gebonden aan de beharing, aan de veeren, aan de schubben, aan de huidcellen zelve, in hare schijnbare grilligheid zoo buitengewoon constant, en daardoor een der belangrijke kenmerken voor de systematische rangschikking der dieren, reikt evenwel veel verder. Dit hier nader uit te werken, zou zijn uilen naar Athene dragen.

Ontwikkelingsgeschiedkundig is de huidpigmentvorming nu eens met den haaraanleg, dan weer met den aanleg en de rangschikking van de bloedvaten van de huid, dan weer met de innervatie, speciaal met de segmentaalinnervatie van de huid in verband gebracht. Het verband te zoeken van het huidpigment met de verdeeling der bloedvaten van de huid lag voor de hand, waar, ten minste voor bepaalde pigmentsoorten, een verband tusschen het pigment en de bloedkleurstof bestaat, maar om, zooals ZeNNiCK dit deed, een direct verband tusschen de verdeeling van de bloedvaten en de pigmentatie van bepaalde cellen of celgroepen in de huid aan te nemen, in dien zin, dat de pigmentcellen langs bepaalde bloedvaten de huid bereiken of speciaal ter plaatse van de samenvloeiing van de kleine bloedvaten in de huidcellen zouden ontstaan, waarbij dus de rangschikking van de bloedvaten het primaire zou zijn, is zeker wel onjuist en geeft aanleiding tot verwarring en tot verwisseling van oorzaak en gevolg. Dat de pigmentatie samenhangt met en dikwijls onder den invloed staat van de huidinnervatie, lijdt geen twijfel. Men denke slechts aan de onderzoekingen van vaN RIJNBERK over den invloed van het sympathische zenuwstelsel op de verandering van pigmentatie en de aanpassing van de huidkleur aan de kleur van de omgeving bij de platvisschen. Dat men bij de dikwijls op zoo frappante wijze met de segmentale innervatiegebieden van de huid overeenstemmende streepof vlekpigmentatie van verschillende zoogdieren (men denke slechts aan de zebra's, aan de „Hollander” konijntjes, enz.) een verband zoekt tusschen deze twee verschijnselen, ligt al evenzeer voor de hand 
als een verband te zoeken tusschen de pigmentatie en de verdeeling der bloedvaten. Doch ook hierbij is zeer stellig niet de oorzaak van de pigmentatie aangetoond. Zelfs al kon men aantoonen, dat de pigmentatie een segmentaal karakter vertoont, d. w. z. dat op elk huidsegment een bepaald kleurpatroon terug te vinden is (cf. BoLK), dan is daarmede nog niets omtrent den oorzaak van de pigmentatie 'gezegd. Een algemeen principe wordt ons hierdoor niet verschaft.

In de laatste jaren nu heeft HAECKER getracht, aan te toonen, dat dit algemeene principe voor de pigmentatie, de ontwikkeling en rangschikking van de pigmentvlekken, zoowel bij de behaarde zoogdieren als bij de vogels en de lagere dieren, gezocht moet worden in den rhythmischen groei, dien de verschillende deelen van de huid gedurende hunne ontwikkeling vertoonen, „das ausgesprochen rhythmische Wachstum flächenhafter Organe, verbunden mit rhythmischer Differenzierung, in unserem Fall der Wachstums- und Teilungsrhythmus der Haut, der manchmal in Korrelation mit dem Wachstumsrhythmus der Körpermetameren steht, manchmal aber in weiterem Umfang autonom ist". (HAECKER, pag. 189).

Dat deze rhythmische groei met de ontwikkeling van de huidpigmentatie in verband kan staan, is volgens HAECKER plausibel, omdat zoowel onder pathologische omstandigheden als bij normale verhoudingen pigmentvorming juist daar pleegt op te treden, waar levendige groei- en stofwisselingsprocessen plaats vinden, of in voorbereiding zijn. Waar nu bijvoorbeeld de haarvorming een bepaalde groepeering van de elementen doet zien, is het best te begrijpen, dat in de pigmentatie van de huid ook deze zelfde groepeering tot uiting komt. Men heeft zich dan echter af te vragen wat hier het primaire is, en in hoeverre verschillen in kleurstofophooping in de huid kunnen tot stand komen door rhythmische groeiverhoudingen in de huid buiten de haarvorming om.

Het bezit van een uitgebreide collectie embryonen van vleermuizen, speciaal van megachiropteren (Rousettus amplexicaudatus Dobs.) bracht mij er toe de ontwikkeling van de huidpigmentatie bij deze diervormen van uit de boven beschreven gezichtspunten beschouwd, na te gaan. Juist de eigenaardige egale grauwbruine kleur van deze dieren biedt in hare eenvoudige verhoudingen een goed uitgangspunt.

De huidpigmentatie ontwikkelt zich bij deze dieren (en hetzelfde is het geval bij Vespertilio en

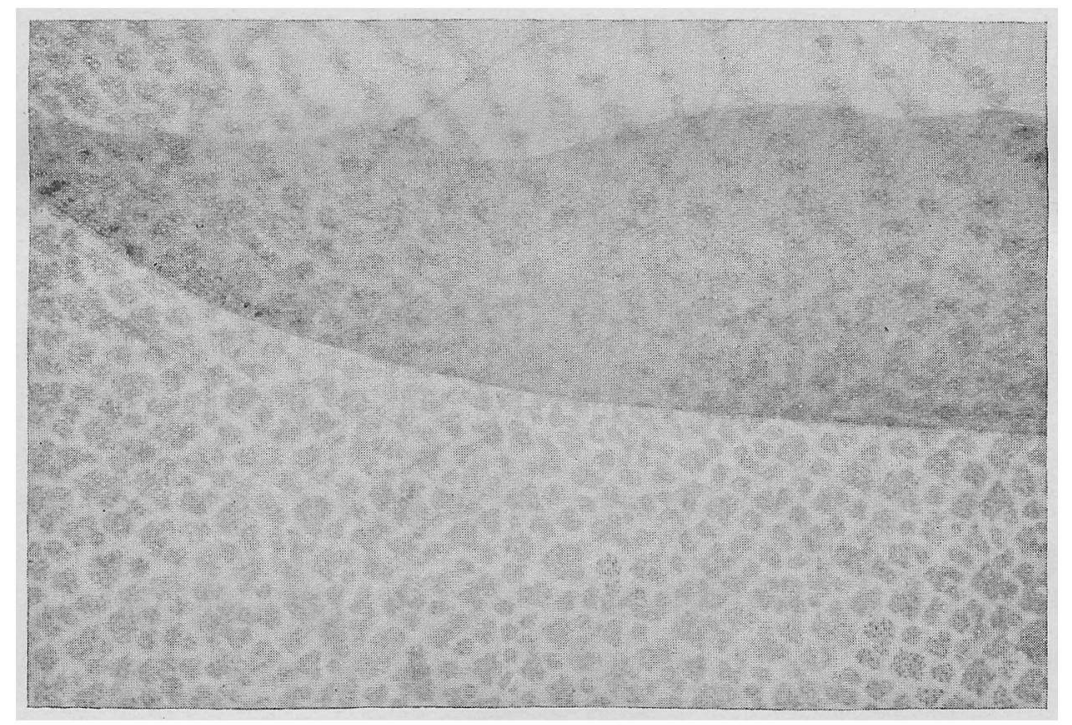

Fig. 1. Stukje huid met vleugelplooi van een embryo van $21 \mathrm{mM}$. lengte, ongekleurd, doorzichtig gemaakt en bij doorvallend licht gephotographeerd. Vergr. 40 maal. Vesperugo) reeds vroeg. Embryonen van $20 \mathrm{mM}$. kruinstuitlengte vertoonen reeds (bij in formol gefixeerde exemplaren) een eigenaardige verkleuring van de huid, die op bepaalde plaatsen, zooals de snuit, de omgeving van de neusgaten, het achterhoofd, den rug en de stuit, eerder optreedt, gaandeweg sterker wordt, en al bij embryonen van $24 \mathrm{mM}$. het geheele diertje een eigenaardigen grauwgelen tint geeft, die wel op die gedeelten van het lichaam, waar zij het eerst is opgetreden, ook later donkerder blijft, doch toch een verder vrijwel gelijkmatige kleur (geen mozaikteekening) aan de huid geeft. Alleen daar, waar zich tusschen den aanleg van de voorste en achterste extremiteiten de vleugelplooien in de huid ontwikkelen, zien wij een uiterst fijne streeping in de richting van de huidplooiontwikkeling.

Bekijkt men nu echter de huid met behulp van een sterke loupe, dan verkrijgt men niet het beeld van een egale pigmentatie, doch de kleurstof blijkt in uiterst regelmatig gevormde, scherp omlijnde groepjes verdeeld te zijn. De eigenaardige vorm dezer kleurstofvlekken komt het best uit, 
als men een stukje van de huid losprepareert, en (bijv. in cederolie) doorzichtig maakt. In fig. 1 is een photo, bij doorvallend licht genomen van een dergelijk geprepareerd stukje huid bij een vergrooting van ongeveer 40 maal weergegeven. Men ziet den eigenaardigen vorm van de kleurstofvlekken, hun eenigszins ruitvormige gedaante, hun verschillen in grootte, terwijl dikwijls dan enkele kleinere kleurstofvlekken samen een ruit vormen van dezelfde grootte als de door één enkele vlek gevormde. De kleurstofvlekken zijn scherp omgrensd, van een uitloopen van de kleur en van langzame overgang is niets te merken. In vorm en regelmaat herinneren de vlekken eenigszins aan het „schaakbordtype” van HAECKER, doch als de vlekken eenvoudig de uiting waren van een dergelijken rhythmischen groei van de huid, zou men toch een regelmatig uitloopen van de kleurstof in intensiteit van 't centrum van de vlek naar de peripherie verwachten.

Zoowel langs de rug en de nek als langs de zijden van het diertje, overgaande op de buik vindt men deze typisch gevormde kleurstofvlekken, steeds van dezelfde grootte en vorm. Doch op één bepaalde plaats blijkt een eigenaardige afwijking van dit type te bestaan, een afwijking, die er ons juist weer toe brengt, toch een bepaald verband tusschen de pigmentvorming en de groeiverhoudingen van de huid te veronderstellen. Zooals bekend is, ontwikkelt zich reeds bij zeer jonge embryonen van chiropteren een huidplooi tusschen de voorste en achterste extremiteiten, terwijl al spoedig de vingers van de voorste extremiteit zich tot de voor de vleermuizen zoo karakteristieke lange vleugelspanners gaan ontwikkelen. Hier heeft dus een zeer sterke groei van de huid in één bepaalde richting plaats, en onderzoekt men nu daar ter plaatse de rangschikking van de pigmentvlekken, dan blijken deze in lange rijen achter elkaar te gaan liggen, zooals uit het bovenste gedeelte van fig. 1, waar

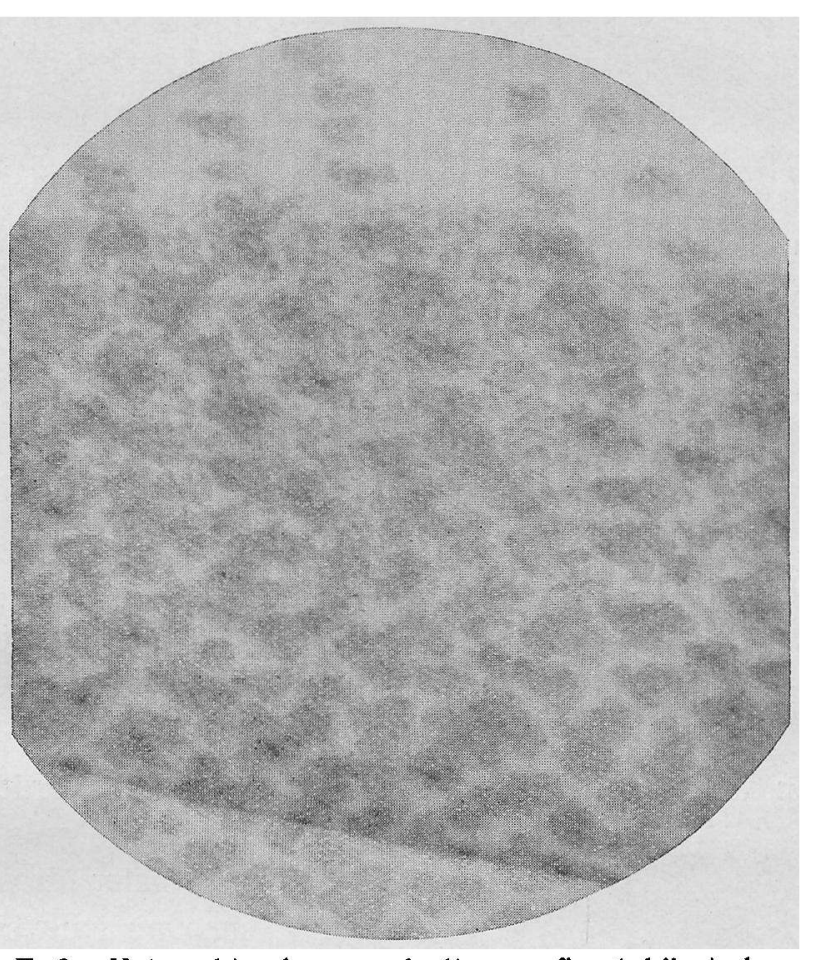

F. 2. Het rechter bovengedeelte van fig. 1 bij sterker vergrooting. Overgang van de kleurstofvlekken in rijen op de vleugelplooi.

juist de huidplooi zich uit de laterale huidstreek ontwikkelt (langs de gebogen lijn), duidelijk blijkt. In fig. 2 is een gedeelte van deze plaats bij sterker vergrooting weergegeven. Zoo komen op de vleugels kleurstofstrepen tot stand, die, zooals bijv. reeds op de afbeeldingen van het onderzoek van ScHöBL uit 't jaar 1871 te zien is, ook bij den volwassen vleermuis nog duidelijk voorhanden zijn, en die allen in één richting loopen, de groeirichting van de huidplooi gedurende hare ontwikkeling.

Is nu echter deze kleurstofteekening, dit patroon, een primair verschijnsel, terug te brengen tot rhythmische groeiverhoudingen van de huid in den zin van HAECKER?

Om dit uit te maken moeten wij de ontwikkeling van het haarkleed nagaan.

Over het algemeen vertoont het haarkleed van de chiropteren weinig karakteristieke eigenschappen. Volgens DE MEIJERE bezitten de chiropteren in den regel verstrooide haren, en zijn bij Cynonycteris collaris de haren in eenvoudige groepen van 5 tot 7 stuks saamgevoegd. Op een andere plaats geeft DE MEjJere aan, dat op den rug bij Pteropus de haren in kleine afgeronde groepen staan, doch "echten Bündel” ontbreken bij chiropteren volkomen. „Den Chiropteren sind in der Regel zerstreute Haare eigen, ohne dass eine bestimmte Anordnung sichtbar ist" '). Volgens LEYDIG staan de haren op de vleugels in kleine groepen van ongeveer 5 stuks (Rhynolophus, Nycteris, Phyllostoma).

Bij volwassen dieren komt dit uit, maar als men de ontwikkeling van het haarkleed bij de embryonen nagaat, blijken de haren niet onregelmatig verspreid te staan, doch zij vertoonen juist dezelfde groepvorming als de pigmentvlekken dit deden. En dit geldt niet alleen voor Rousettus, maar ook embryonen van Pteropus, van Vespertilio murinus, van Vesperugo noctula vertoonen precies hetzelfde beeld.

1) DE MEIJERE. Morphologisches Jahrbuch. Bd. 21, pag. 350 . 
In fig. 3 is een dergelijk beeld weergegeven, ontleend aan een reeks tangentiale doorsneden door een stukje rughuid van een embryo van Rousettus van $21 \mathrm{mM}$. lengte, met haematoxyline en eosine gekleurd. Men ziet, hoe in dit beeld volkomen dezelfde groepeering en vlekvorming te voor-

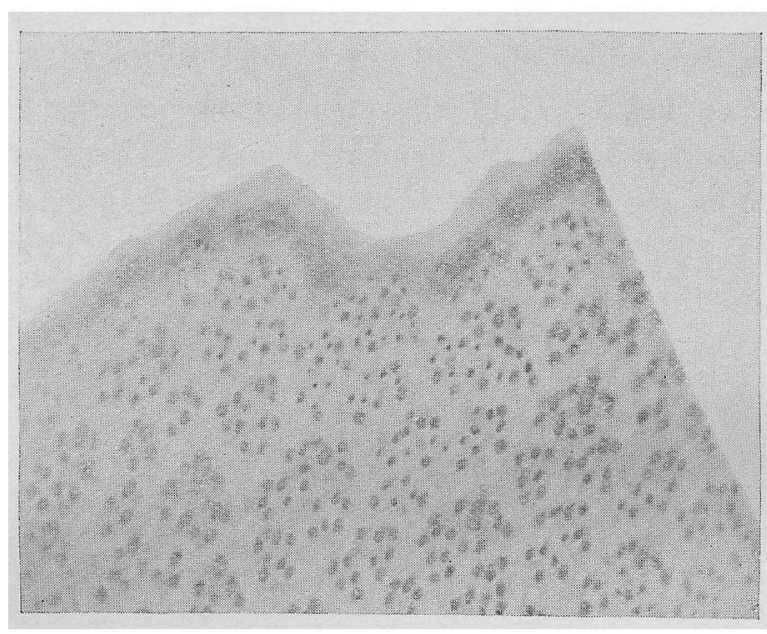

Fig. 3. Tangentiaalsnede door de huid van een embryo van Rousettus van $21 \mathrm{mM}$. lengte. Groepvorming van den haaraanleg. schijn treedt als bij de photo van de pigmentvlekken in de doorzichtig gemaakte ongekleurde huid. Beide verschijnselen dekken elkaar geheel. De haren vormen bij hun aanleg juist dezelfde groepen als de pigmentvlekken, zij staan in bundels bijeen. En dat men hier werkelijk met aanleg van haren en niet van zweetklieren of talgklieren te maken heeft, blijkt, als men oudere embryonen of voldragen dieren onderzoekt. Een tangentiale doorsnede door de huid van een pasgeboren dier vertoont aan hare onderzijde de doorgesneden haarwortels juist in dezelfde groepeering als bij fig. 3. Eerst later, in samenhang met den groei van de huid, wijken de haren van een zelfde groep uiteen, worden waarschijnlijk nog nieuwe haren aangelegd, en verkrijgen de haren de onregelmatige (of beter gelijkmatig verstrooide) inplanting, die door DE MEIJERE werd beschreven.

Eigenaardig is hierbij het volgende: als men huiddoorsneden van jongere embryonen onderzoekt, waar de haaraanleg juist begonnen is, is er nog geen sprake van een groepvorming van de punten van aanleg, doch men ziet regelmatig verspreid groote alleenstaande haren in aanleg. In fig. 4 is een dergelijk beeld bij dezelfde vergrooting gephotographeerd en gereproduceerd als fig. 3, dat van een veel grooter embryo afkomstig was. Er worden eerst enkelvoudige groote haren aangelegd („stam-

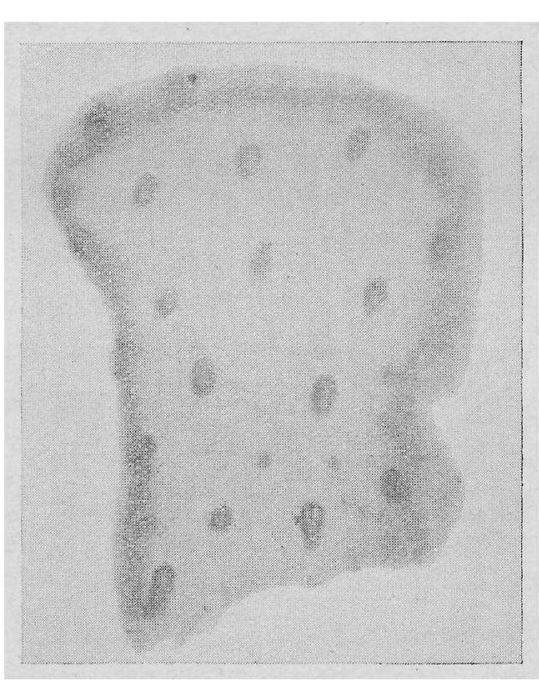

Fig. 4. Tangentiaal doorsnede door de huid uit de sakraalstreek van een embryo van Rousettus van $15 \mathrm{mM}$. lengte. Ontwikkeling van de stamharen, bij dezelf de vergrooting gephotographeerd als fig. 3. haren" volgens de terminologie van DE MEIJERE) en dan groepeeren zich later daaromheen de andere haren van de groep. En bekijkt men nu nauwkeurig het beeld van fig. 3, dan blijken ook daar nog in dezelfde groep de haren niet allen gelijk van kaliber te zijn, doch één van de haren, in alle groepen aan dezelfde zijde gelegen en naar dezelfde zijde gekeerd, is veel grooter dan de andere. Deze laatsten (de „bijharen" van DE MEIJERE) zijn allen van dezelfde grootte. De groepen der haren zijn dus "echte" groepen.

De groepeering van de pigmentvlekken komt dus overeen met die van de haren. En dit is volkomen begrijpelijk. Want als men microscopisch de ontwikkeling van de kleurstof in de huid nagaat, blijkt deze volkomen aan de haren gebonden te zijn. Ook later. Als men van een jong dier, dat reeds de eigenaardige donker grauwbruine rossige tint van den volwassen Rousettus heeft aangenomen, een stukje huid doorzichtig makkt, zijn alleen de haren en hun wortels gepigmenteerd, doch daartusschen is de huid nagenoeg glashelder doorschijnend.

Zoodra de haaraanleg zich vertoont, ziet men ook de eerste pigmentkorreltjes in de cellen van de epidermis liggen of van uit het bindweefsel er in binnendringen, juist daar waar de celwoekering van den haaraanleg plaats vindt. Dit is dus volkomen in overeenstemming met het algemeen principe van HAECKER, dat men daar waar krachtige groei optreedt, waar kerndeelingen in groot aantal te vinden zijn, waar een groeicentrum zich bevindt, de pigmentatie ziet optreden. Maar men vraagt zich toch wel eetis af, of hiermede wel een algemeen geldend principe kan worden vastgesteld. Zooals uit 't bovenstaande bleek, is ook later. de pigmentatie van de huid aan de haren gebonden. Dat bij den haaraanleg juist elk haar een centrum van groei met tal van kerndeelingen vormt, is natuurlijk. Maar ook bij de ontwikkeling van de zweetklieren vinden wij dezelfde versnelling van den groei met tal 
van kerndeelingen, doch van pigmentatie geen spoor. Bij de ontwikkeling van de vleugelplooien zien wij wel de boven beschreven rangschikking van de haar-pigment-groepen in lengterijen, maar van een pigmentatie van de toch ook snel groeiende epidermis daartusschen juist hier geen spoor. De zich snel ontwikkelende oorschelpen liggen bij de gepigmenteerde embryonen als witte vlekken in de bruingekleurde (behaarde!) omgeving. Kortom, het vraagstuk is niet zoo eenvoudig, als het op 't eerste gezicht zou lijken. En daarbij komt ten slotte het volgende. Bij embryonen met beginnende haarvorming en haarpigmentatie ziet men behalve het aan dien haaraanleg gebonden pigment nog een tweede pigmentatie van de huid optreden, een afzetting van fijne bruine pigmentkorreltjes in de cellen van de buitenste cellagen van de (nog niet verhoornende) epidermis, deels een directe afzetting in de cellen van het epidermisepithelium zelve, deels liggende in vertakte pigmentcellen die uit de onderste cellagen in de bovenste doordringen. Deze pigmentatie is diffuus, geeft de epidermis een egale lichtbruine kleur, bekommert zich absoluut niet om de punten van haaraanleg of andere groeicentra, en vertoont zich juist niet of in veel mindere mate in de epidermis van de vleugelplooien. In fig. 2 schemert deze pigmentatie van de huid onder de basis van de vleugelplooi door de tusschen de in lengterijen liggende groepen van pigmentkorrels van den haaraanleg ongekleurd gebleven huidgedeelten van den vleugelplooi zelf heen.

Dit zijn slechts enkele verspreide waarnemingen. Doch zij versterkten in mij den indruk, dat althans bij de zoogdieren met hun karakteristieke beharing het algemeene groeiprincipe van HAECKER nog niet in staat is, ons een juist beeld van den o o rzaak der pigmentatie en van hare verdeeling over de verschillende plekken van de huid te verschaffen.

En tevens blijkt uit deze waarnemingen duidelijk, dat men, als men de rangschikking van de haren bij de zoogdieren in verband met het oorspronkelijke schubkleed van de huid wil bestudeeren, men zich niet mag beperken tot het onderzoek van de volwassen vormen, doch dat men steeds ook de embryonen moet onderzoeken, vooral de jongere stadien, daar de haren in aanleg dikwijls een karakteristieke groepeering vertoonen, die later geheel of gedeeltelijk verloren kan gaan. 